\title{
Urgences
}

\section{Bicyclettes praticables aux vents de l'intérieur}

\section{Mona Lisa}

Numéro 20, mai 1988

Appellation contrôlée

URI : https://id.erudit.org/iderudit/025472ar

DOI : https://doi.org/10.7202/025472ar

Aller au sommaire du numéro

Éditeur(s)

Urgences

ISSN

0226-9554 (imprimé)

1927-3924 (numérique)

Découvrir la revue

Citer ce document

Lisa, M. (1988). Bicyclettes praticables aux vents de l'intérieur. Urgences, (20), 27-27. https://doi.org/10.7202/025472ar d'utilisation que vous pouvez consulter en ligne.

https://apropos.erudit.org/fr/usagers/politique-dutilisation/ 


\section{MONA LISA \\ Bicyclettes praticables aux vents de l'intérieur}

- la terre et l'eau

Sans doute il y a une mer dont on ne connaît pas le nom dans ce vent, une recette pour sarcler le temps des herbes et des jours inutiles. Sans doute il y a, dans ce bouleversement de nous-mêmes, une voie qui cherche aventure pour que l'avenir reste ouvert.

Car le corps de la terre a aussi un océan qui monte et qui descend toutes les six heures avec la respiration du monde. Ne sommes-nous pas sauvés par cette chose réelle devant nos yeux qui jamais ne se lassent aux points de tangente?

Ainsi pour faire le tour de la terre, il faut ventiler et ensoleiller ses études, jouer dans les vagues de son propre corps. Tout passe par ces points obligés des humeurs circulant par canaux quand le corps se divise, distraitement docile à quelque fin profonde.

Mais un jeu de nervures échoue toujours aux volets des fenêtres, à cette heure, jamais la même et la même pourtant, où un libreéchange du souffle joue contre la réalité.

Alors le meilleur de nos instants fonde un point du temps écoulé et repris dans le présent de l'arbre et de son flottement d'avenir. Cette extase de l'espérance qui nous oublie pour l'écho.

Travailler pour l'incertain. Enfanter des époques au treuil secret des villes où l'on fait choix d'une certaine image du Nouveau Monde, parmi les feuilles et les événements du milieu des choses quand le monde est sans espérance, puis voguer entre les infinis des différentes masses continentales qui flottent sur le sima pour enlever à la résistance des océans les sels de leur âge sur des bicyclettes praticables aux vents de l'intérieur. 